\title{
Using a professional DSLR camera to measure total shrinkage of resin composites
}

\section{Julyana Dumas Santos SILVA ${ }^{(a)}$ ii Lorena Aparecida Santos de FREITAS(a) \\ Vitória Ariella Silveira e SILVA(a) Tainah Costa FIRMIANO(a) (DD Daranee TANTBIROJN(b) \\ Antheunis VERSLUIS(c) Crisnicaw VERÍSSIMO(a) iD}

(a) Universidade Federal de Goiás - UFG, School of Dentistry, Department of Oral Rehabilitation, Goiania, GO, Brazil.

(b) University of Tennessee Health Science Center-UTHSC, College of Dentistry, Department of General Dentistry, Memphis, TN, EUA.

(c) University of Tennessee Health Science Center - UTHSC, College of Dentistry, Department of Bioscience Research, Memphis, TN, EUA.

Declaration of Interests: The authors certify that they have no commercial or associative interest that represents a conflict of interest in connection with the manuscript.

\section{Corresponding Author:}

Crisnicaw Veríssimo

E-mail: crisnicaw.verissimo@ufg.br

https://doi.org/10.1590/1807-3107bor-2022.vol36.0009

Submitted: April 13, 2021

Accepted for publication: September 9, 2021 Last revision: September 16, 2021
Abstract: This study evaluated the optical method for measuring free total shrinkage using a Digital Single Lens Reflex (DSLR) camera. Eight composites were evaluated, conventional, bulk fill and low-shrinkage: Z100 (3M Oral Care), Gradia Direct Anterior (GC corporation), Spectra Smart (Dentsply), Filtek Z350 XT (3M Oral Care), Aura Bulk Fill (SDI), Vittra APS (FGM), Opus Bulk Fill APS (FGM), and Beautifil II LS (Shofu Inc.). The samples ( $6 \mathrm{~mm}$ diameter and $1.5 \mathrm{~mm}$ thick, $\mathrm{n}=10)$ were placed on a polyvinylsiloxane impression material. An image of the uncured sample was captured using a DSLR camera with $105 \mathrm{~mm}$ macro lens and a ring flash. Samples were light cured with a $700 \mathrm{~mW} / \mathrm{cm}^{2} \mathrm{LED}$ light-cure unit for 40s. Post-polymerization images were captured at 2, 10 and $60 \mathrm{~min}$. Projected circumferential areas of the specimens were drawn using the ImageJ software. Volumetric total shrinkage was calculated from the ratio of the areas obtained from pre- and post-curing. Results were analyzed using One-way ANOVA $(\alpha=0.05)$ and Tukey test. Volumetric total shrinkage values were significantly different among the composite materials $(\mathrm{p}<.001)$. The volumetric shrinkage (\%) mean and results of Tukey test at 60 min were: Z100: $3.45 \pm 0.30$ (A); Gradia Direct Anterior: $3.00 \pm 0.23$ (B); Spectra Smart $2.89 \pm 0.35$ (B); Filtek Z350 XT: $2.65 \pm 0.37$ (BC); Aura Bulk Fill: $2.42 \pm 0.25$ (CD); Vittra APS: $2.14 \pm 0.35$ (DE); Opus Bulk Fill APS: $1.91 \pm 0.24$ (E); Beautifil II LS: $1.18 \pm 0.16(F)$. The optical method using a DSLR camera, was suitable for total shrinkage evaluation and will allow assessment of total shrinkage without the need for specialized equipment.

Keywords: Composite Resins; Polymerization; Image Processin, Computer-Assisted; Optical Phenomena.

\section{Introduction}

The constant improvement in restorative dentistry, aiming at more conservative, aesthetic and long-time treatments, has made the resin composite a remarkable treatment option. ${ }^{1-5}$ However, despite the advances in materials, studies still show the presence of microleakage, secondary caries, crack propagation in enamel and postoperative sensitivity, affecting the clinical longevity of restorations., ${ }^{3,-14}$ Such factors are related to polymerization shrinkage and polymerization shrinkage stress, an inherent characteristic of resin-based materials. ${ }^{15}$ 
This shrinkage occurs when monomers form a three-dimensional polymer network. ${ }^{16}$ Shrinkage values have been measured using various methods. ${ }^{17,18}$ One common technique is to measure the displaced volume of a composite sample immersed in a liquid before and after curing. ${ }^{18} \mathrm{~A}$ shrinkage value obtained with this method is the total shrinkage because it measures the entire amount of dimensional change of the composite during polymerization. It is important to note that any method that restricts free contraction cannot measure all shrinkage because some of its contraction movement is prevented. ${ }^{17}$ Total shrinkage is primarily a function of degree of conversion, and therefore can reflect the dynamics of a polymer network formation, type of monomer chosen for the formulation, and the nature of polymerization. Therefore, total shrinkage values can be very useful in improving/developing resin-based material formulations. ${ }^{16,17,18}$

When a resin composite cures, the material is transformed from a viscous paste to a solid material. In the viscous stage, the flow of the composite can relax any developing shrinkage stress (pre-gel shrinkage) ${ }^{3,8,17}$ However, when the material becomes more rigid such stress relieving flow is inhibited and further changes in volume can lead to irreversable stress (post-gel shrinkage). ${ }^{3,8,17}$ Therefore, residual shrinkage stresses are generated only during post-gel shrinkage, when the cured material has become unable to relieve stresses generated by the restraints imposed by external bonding conditions. ${ }^{8}$ Although the post-gel shrinkage is more relevant for clinicians if polymerization shrinkage stress is their primary concern, total shrinkage (the sum of pre- and post-gel shrinkage) remains an important property when dimensional stability is important and for the understanding and development of new resin composites. A recent development in dentistry are bulk fill and low-shrinkage composites, for example, which have modifications in the dynamics of polymer chain formation that reduce polymerization shrinkage and, indirectly, may contribute to reduced residual stresses. 3,7,8,17 These new material developments were designed to improve the performance of restorative procedures. In addition, bulk fill composites aim to simplify the placement procedure. This is accomplished by improving their ability to polymerize deeper, reaching up to $4 \mathrm{~mm}$, which allows larger (thicker) increments. ${ }^{6,19,20,21}$ Reducing the number of increments is also beneficial for shrinkage stress reduction. In addition, bulk fill resins have demonstrated lower post-gel shrinkage values and, consequently, reduced stresses and cuspal deflection. ${ }^{6,19,20,21}$

Various methods have been used to measure spatial/volumetric shrinkage (dilatometers, ${ }^{22,23,24}$ video-imaging ${ }^{26}$ optical method, ${ }^{17}$ microcomputed tomography ${ }^{27}$ ) or linear shrinkage (linometers, ${ }^{25}$ strain gauge method ${ }^{28}$ ). Despite shrinkage being a simple and well-established concept, most shrinkage measurement methods require specialized costly equipment. . $^{1727,30,31,32}$ Moreover, not all these experimental methods measure the same shrinkage because testing setups affect the ratio of pre- and post-gel shrinkage they will register. ${ }^{29}$ True total shrinkage requires free shrinkage. Many methods need to fix the tested specimens to a substrate, and consequently free-shrinkage is not actually achieved.

A simplified optical method for evaluating total shrinkage in restorative composites was introduced in 2015. ${ }^{17}$ Specimens of non-polymerized composite resins were positioned on a slick silicone base. Under a stereomicroscope with an attached charge-coupled device camera, images were taken pre- and post-polymerization. The projected area of each specimen was then measured using public domain software ImageJ (http://imagej.nih.gov/ $\mathrm{ij} /$ ). The authors emphasize the importance in the selection of silicone color, since, when evaluated in the software, the images should present adequate contrast between the specimen and the silicone base. However, a stereomicroscope with adequate charge-coupled device camera may not always be available. Therefore, the present study proposes the use of a digital DSLR (Digital Single Lens Reflex) camera, with $105 \mathrm{~mm}$ macro lens and ring flash, which is a common equipment in dental clinics and research centers, instead of a stereomicroscope.

DSLR cameras use a set of mirrors and a pentaprism that allow the image to be viewed through the optical viewfinder. This image enters the lens and is later captured by the mirror, responsible for transferring it to a digital sensor that, in turn, stores the photograph. 
Thus, the viewfinder image is exactly like that captured by the lenses, making the DSLR camera a high precision equipment that provides details suitable for the optical evaluation of shrinkage.

The present study introduced and evaluated a new approach to optically measure free shrinkage of different brands of conventional, bulk fill, and low-shrinkage restorative composites using a DSLR camera with $105 \mathrm{~mm}$ macro lens and a ring flash. The tested null hypothesis was that there would be no difference in volumetric total shrinkage values between conventional, bulk fill, and low-shrinkage composites evaluated by the DSLR optical method.

\section{Methodology}

A DLSR Camera (Nikon D5200, Nikon Corporation, Japan Optical Industries Co., Tokyo, Japan) attached to a ring flash (EM-140DG, Sigma, Ronkonkoma, EUA) was fixed to a mounted camera monopod desk (Figure 1) $15 \mathrm{~cm}$ above the sample. A $105 \mathrm{~mm}$ macro lens was attached to the camera body (AF-S VR Micro-Nikkor 105 mm f/2.8G IF-ED, Nikon Corporation, Japan Optical Industries Co.). The exposure was adjusted using the following camera set-up: Aperture: (f29); ISO: (100); and shutter speed: (1/125). The manual mode was selected. The ring flash intensity was set to $1 / 16$ in manual mode. The camera live mode was turned on in order to see the specimen (Figures 1A and 1B). A polymerized composite sample was placed on a silicone platform and the focus of the camera was adjusted. Camera/lens autofocus function was used and the largest magnification that showed the entire was used. Focus of the camera was not changed until the experiment was completed.

Eight commercially available restorative composites were evaluated, consisting of five conventional composites (Z100, 3M Oral Care, St Paul, USA; Gradia Direct Anterior, GC Corporation, Tokyo, Japan; Spectra Smart, Dentsply Sirona, York, USA; Filtek Z350 XT, 3M Oral Care, St Paul, USA; Vittra APS, FGM Dental Products, Joinville, Brasil), two bulk fill composites (Opus Bulk Fill APS, FGM Dental Products, Joinville, Brasil; Aura Bulk Fill, SDI, Bayswater, Victoria, Australia) and one low-shrinkage composite resin Beautifil II LS (Shofu Inc., Kyoto, Japan) according to Table 1.

An amount of composite was determined with a $6 \times 1.5 \mathrm{~mm}$ spacer, molded into a round dome shape by a single operator to standardize the samples. After that, the sample was placed on the silicone platform (Figure 2A). An uncured composite sample was placed on the smooth green surface of the silicone platform, made from polyvinylsiloxane impression material (Scan Regular, Yller Biomateriais, Pelotas, Brazil). This color was selected after testing the contrast of different impression material colors for image analysis in a
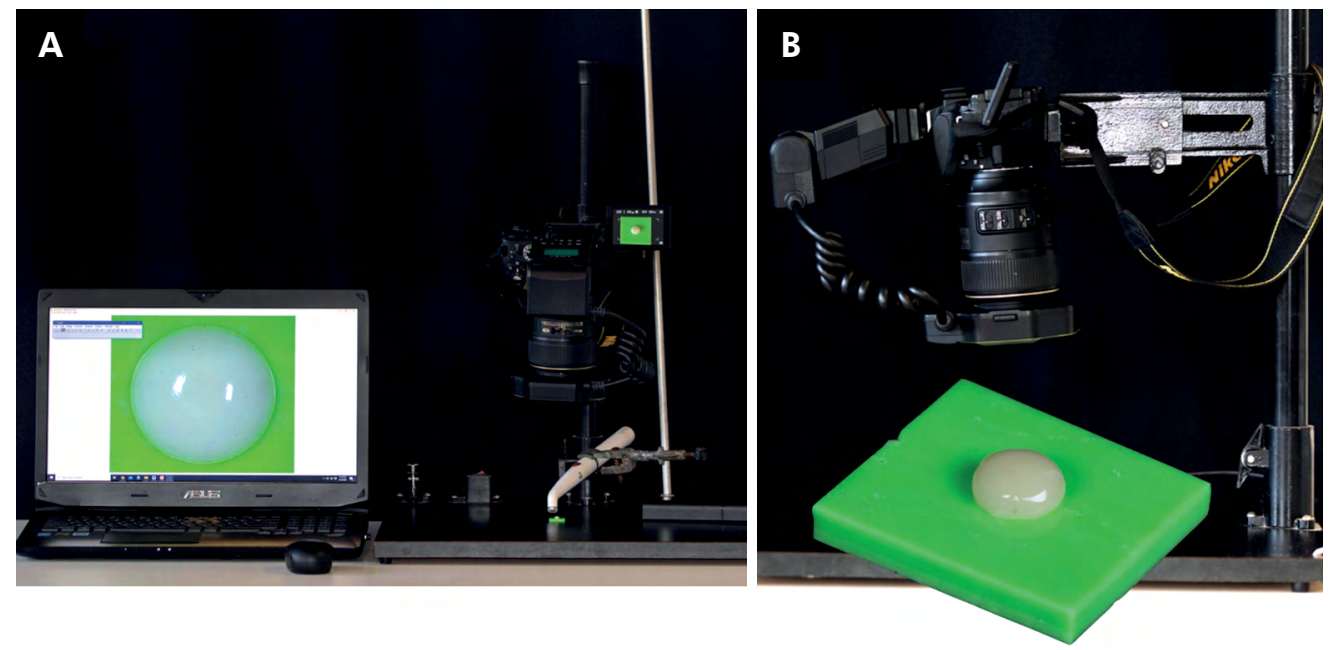

Figure 1. Experimental setup of the optical method using a DSLR camera, $105 \mathrm{~mm}$ macro lens and a ring flash. Frontal view (A); Side view (B). 
Table 1. Material information.

\begin{tabular}{|c|c|c|c|c|}
\hline Composite & Composition & Type & Batch\# & Manufacturer \\
\hline Z100 & $\begin{array}{c}\text { Treated silanized ceramics,TEGDMA, bis-GMA, } \\
\text { 2-Benzotriazolyl-4-methylphenol } \\
\text { Filler loading: } 66 \mathrm{vol}(\%)\end{array}$ & $\begin{array}{l}\text { Conventional } \\
\text { composite }\end{array}$ & 1820900228 & $\begin{array}{l}\text { 3M Oral Care, } \\
\text { St Paul, USA }\end{array}$ \\
\hline $\begin{array}{l}\text { Gradia Direct } \\
\text { Anterior }\end{array}$ & $\begin{array}{c}\text { Methacrylate monomers } 27 \mathrm{w}+\% \text {. Silica (particle size } 0.85 \mu \mathrm{m} \text { ) } \\
\qquad 38 \mathrm{w} \% \text {, prepolymerized filler } 35 \mathrm{w}+\%\end{array}$ & $\begin{array}{l}\text { Conventional } \\
\text { composite }\end{array}$ & 1607072 & $\begin{array}{l}\text { GC Corporation, } \\
\text { Tokyo, Japan }\end{array}$ \\
\hline Spectra Smart & $\begin{array}{c}\text { Glass Powder, Silica, Colloidal Hydrophobic, Dimethacrylate, } \\
\text { Benzophenone III, EDAB, FluBlau Concentrate, } \\
\text { Camphorquinone, BHT Butylated Hydroxytolvene, Yellow Iron } \\
\text { Oxide, Red Iron Oxide, Black Iron Oxide and Titanium Dioxide } \\
\text { Filler loading: } 57-60 \text { vol(\%) }\end{array}$ & $\begin{array}{l}\text { Conventional } \\
\text { composite }\end{array}$ & 237450l & $\begin{array}{l}\text { Dentsply Sirona, } \\
\text { York, USA }\end{array}$ \\
\hline $\begin{array}{l}\text { Filtek } \\
\text { Z350 XT }\end{array}$ & $\begin{array}{c}\text { Treated silanized ceramics, Silane treated silica, UDMA; } \\
\text { bis- EMA (6), bis-GMA, Zirconia ceramic (66402-68-4), } \\
\text { modifed surface with 3-methacrylonoxypropyltrimetoxy silane } \\
\text { (2530-85-0), bulk material, PEGDMA, TEGDMA } \\
\text { Filler loading: } 60 \text { vol (\%) }\end{array}$ & $\begin{array}{l}\text { Conventional } \\
\text { composite }\end{array}$ & 652583 & $\begin{array}{l}\text { 3M Oral Care, } \\
\text { St Paul, USA }\end{array}$ \\
\hline Aura Bulk Fill & $\begin{array}{c}\text { Silica, Barium, UDMA, Bis-EMA, Bis-GMA } \\
\text { Filler loading: } 65 \mathrm{vol}(\%)\end{array}$ & $\begin{array}{l}\text { Single increment } \\
\text { composite (Bulk fill) }\end{array}$ & 151148 & $\begin{array}{l}\text { SDI, Bayswater, Perth, } \\
\text { Australia }\end{array}$ \\
\hline Vittra APS & $\begin{array}{l}\text { UDMA,TEGDMA, photoinitiating composition, co-starters, } \\
\text { zirconia charge, silica and pigments } \\
\text { Filler loading: } 52-60 \mathrm{vol}(\%)\end{array}$ & $\begin{array}{l}\text { Conventional } \\
\text { composite }\end{array}$ & 181017 & $\begin{array}{l}\text { FGM Dental } \\
\text { Products, Joinville, BR }\end{array}$ \\
\hline $\begin{array}{l}\text { Opus Bulk Fill } \\
\text { APS }\end{array}$ & $\begin{array}{l}\text { Methacrylic urethane monomers, stabilizers, camphorquinone, } \\
\text { co-initiator, saline silicon dioxide, stabilizers and pigments. } \\
\text { Filler loading: } 67,1 \mathrm{vol}(\%)\end{array}$ & $\begin{array}{l}\text { Single increment } \\
\text { composite (Bulk fill) }\end{array}$ & 220218 & $\begin{array}{l}\text { FGM Dental } \\
\text { Products, Joinville, } \\
\text { Brasil }\end{array}$ \\
\hline Beautifil II LS & $\begin{array}{c}\text { Glass powder, Urethane diacrylate, Bis-MPEPP, Bis-GMA, } \\
\text { TEGDMA, Polymerization initiator, Pigments and others. } \\
\text { Filler loading: } 83 \text { vol (\%) }\end{array}$ & Low Shrinkage & 21925 & $\begin{array}{l}\text { Shofu Inc., Kyoto, } \\
\text { Japan }\end{array}$ \\
\hline
\end{tabular}

Sources: Product's Safety Data Sheet, Product Profiles, Product website, Product Technical Manual.

bis-GMA, bisphenol A diglycidyl ether dimethacrylate; UDMA, diurethane dimethacrylate; TEGDMA, triethylene glycol dimethacrylate;

bis- EMA(6), bisphenol A polyethylene glycol diether dimethacrylate; PEGDMA, polyethylene glycol dimethacrylate; Bis-MPEPP, Bisphenol A

polyethoxy methacrylate.

previous study. ${ }^{17}$ This material surface imposed no restrictions on the movements of the composite samples. No adhesive system was used. The uncured sample was placed below the camera (live mode) and an image was captured (uncured stage, $0 \mathrm{~min}$ ). A $700 \mathrm{~mW} / \mathrm{cm}^{2}$ LED light-curing unit (Radii Cal, Bayswater, Perth, Australia) was fixed approximately $1 \mathrm{~mm}$ above the composite sample. An adjustable support was used to standardize this distance and thus the amount of energy (radiant exitance) for all samples while avoiding contact of the light curing unit tip with the sample. The composite was polymerized for 40 seconds. Post-polymerization images were captured after 2, 10 and 60 minutes. Sample size was 10 per group. All experiments were conducted at room temperature and by a single trained operator.

The pre- and post-polymerization images (*.JPEG) were opened in a public-domain image analysis software (ImageJ, http://imagej.nih.gov/ij/) (Figure 2). Sample outlines were traced by a trained blinded operator using the Polygon selection (Figure 2B). The researcher who traced the samples was not the same as the one who carried-out the experiments to avoid bias. Sample outlines can also be traced using the Wand tracing tool (Figure 2C). Percentage volumetric shrinkage $(S)$ was calculated with the following equation:

$$
S=1-\left[\left(\frac{\text { Acured }}{\text { Auncured }}\right)^{\frac{3}{2}} x\right] 100(\%)
$$

where $\mathrm{A}_{\text {cured }}$ is the projected surface area after curing and $A_{\text {uncured }}$ is the projected uncured surface area. After polymerization, specimens were weighed on a precision digital balance (HR-200, A\&D Company Limited, Tokyo, Japan) (Table 2).

The volumetric total shrinkage (\%) data at $60 \mathrm{~min}$ were tested for homogeneity. Once the homogeneity 

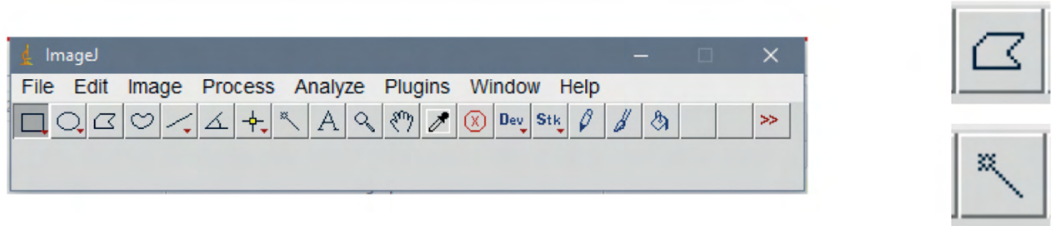

Polygon selections

Wand (tracing) tool
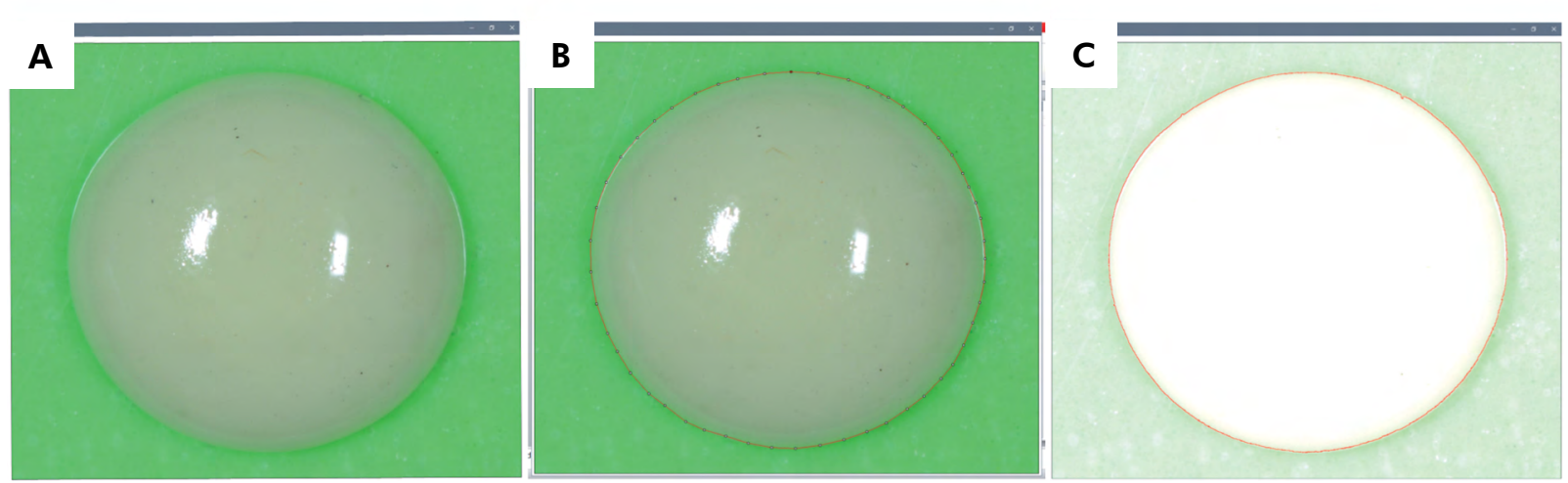

Figure 2. Analysis in the image analysis software (lmage J) of the pre- and post-polymerization sample. Pre-polymerization image (A); the contours of the samples drawn on the captured images with Polygon Selections tool (B); Brightness adjustment for better outline visualization with the Wand Tool (C).

Table 2. Specimens weight (mean \pm standard deviation).

\begin{tabular}{lc}
\hline Composite resin & Specimens weight $(\mathrm{g})$ \\
\hline Z100 & $0.13 \pm 0.005$ \\
Gradia Direct Anterior & $0.11 \pm 0.005$ \\
Spectra Smart & $0.13 \pm 0.006$ \\
Filtek Z350 XT & $0.11 \pm 0.006$ \\
Aura Bulk Fill & $0.10 \pm 0.008$ \\
Vittra APS & $0.11 \pm 0.005$ \\
Opus Bulk Fill APS & $0.12 \pm 0.006$ \\
Beautifil II LS & $0.12 \pm 0.005$ \\
\hline
\end{tabular}

was verified, results were analyzed using One-way ANOVA $(\alpha=0.05)$ and Tukey test (IBMSPSS statistics 24.0, IBM Corp., Armonk, USA).

\section{Results}

Mean volumetric total shrinkage of each composite captured at three intervals $(2,10,60 \mathrm{~min})$ were plotted in Figure 3. The 60-min volumetric shrinkage values (mean \pm standard deviation) and statistical results comparing the eight composites are shown in Table 3.
Shrinkage values were significantly different among the composite materials tested (one-way ANOVA; $\mathrm{p}$ < 0.001). Z100 showed the highest values, followed by Gradia Direct Anterior, statistically similar to Spectra Smart $(p=0.993)$ and Filtek Z350 XT ( $p=0.164)$. Aura Bulk Fill presented intermediate values, statistically similar to Vittra APS ( $p=0.423)$. The lowest values found were for Beautifil II LS, followed by Opus Bulk Fill APS, which was statistically similar to Vittra $\operatorname{APS}(p=0.652)$.

\section{Discussion}

During the polymerization process of resin composites a network of crosslinked polymers is developed that gives the material a hardened and rigid denser structure causing the volumetric shrinkage. ${ }^{16}$ Volume shrinkage is thus an intrinsic characteristic of these materials that reflects the nature of polymer network formation..$^{16,17}$ Different types of volumetric shrinkage can be measured (total, pre-, and/or post-gel shrinkage) depending on the research method. Our study describes a new approach to optically measure free total shrinkage with a DSLR camera. Many different methods 


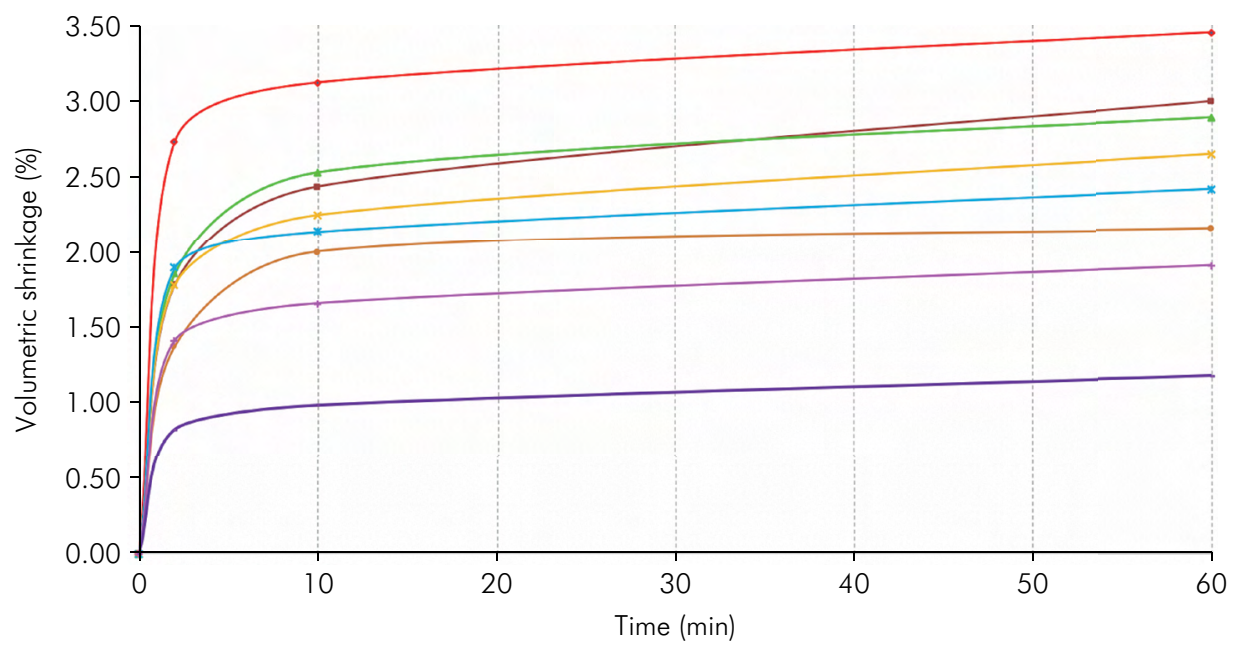

$\rightarrow$-Z100 $\rightarrow$ Gradia direct $\rightarrow$ Spectra smart $\rightarrow$-Filtek Z350 XT $\rightarrow$-Aura bulk fill $\rightarrow$ Vittra APS $\rightarrow$ Opus bulk fill APS $\longrightarrow$ Beautifil II LS

Figure 3. Total shrinkage (volume \%) for the eight restorative composites against time (0-60 $\mathrm{min})$.

Table 3. Percentage volumetric shrinkage (mean \pm standard deviation) at $60 \mathrm{~min}$.

\begin{tabular}{lcc}
\hline Composite resin & Volumetric Shrinkage (\%) & Tukey HSD \\
\hline Z100 & $3.45 \pm 0.30$ & $\mathrm{~A}$ \\
Gradia Direct Anterior & $3.00 \pm 0.23$ & $\mathrm{~B}$ \\
Spectra Smart & $2.89 \pm 0.35$ & $\mathrm{~B}$ \\
Filtek Z350 XT & $2.65 \pm 0.37$ & $\mathrm{BC}$ \\
Aura Bulk Fill & $2.42 \pm 0.25$ & $\mathrm{CD}$ \\
Vittra APS & $2.14 \pm 0.35$ & $\mathrm{DE}$ \\
Opus Bulk Fill APS & $1.91 \pm 0.24$ & $\mathrm{E}$ \\
Beautifil II LS & $1.18 \pm 0.16$ & $\mathrm{~F}$ \\
\hline Different capital letters indicate significant differences between materials.
\end{tabular}

have been used in the literature for measuring polymerization shrinkage. However, most of these methods require specialized equipment and software that may not be available in every dental research laboratory or are costly. Among the various methods for evaluating total shrinkage, the AccuVol method, computerized microtomography and dilatometers may be the most common. Each method has advantages and disadvantages. For example, the dilatometer technique allows real-time measurement, showing the polymerization process, while the scanning time of high-resolution microtomography does not allow shrinkage determination until the polymerization rate has slowed down significantly. One drawback of all three techniques is the requirement to hold the composite sample in place during the test. This means that shrinkage is restricted and therefore the measured value does not represent all free shrinkage. ${ }^{17}$

A simple and inexpensive method for evaluating total shrinkage of the composites was developed to address the equipment availability and free shrinkage issues. ${ }^{17}$ This method used a stereomicroscope and public-domain image analysis software. The present study further simplified the optical shrinkage measurement technique by replacing the stereomicroscope/CCD system with a DSLR camera. DLSR cameras are widely used in clinical departments and dental research laboratories, thus are a very practical option.

To determine the projected surface area, the polygon selection tool was used in Image J software. Through this tool, specimen outlines were obtained at uncured stage, and at 2, 10 and 60 minutes post-polymerization. In this methodology, the use of a silicone platform with a contrasting color helps the manual tracing of the composite specimen's outlines. Filtek Z350 XT composite resin (3M Oral Care) was used for calibrating the values obtained by the DSLR camera. Filtek Z350 XT (Filtek Supreme Ultra) allows consistent comparison because it was previously tested. ${ }^{17}$ A study using a 
stereomicroscope showed a similar value (2.68\%) to the one found in this study $(2.65 \%) .{ }^{17}$ These results can be compared because similar methodology was used except for the image capture. Specimens had the same dimensions, $6 \mathrm{~mm}$ in diameter and $1.5 \mathrm{~mm}$ thick. The light curing units were not the same, but both had similar irradiance values and the time of light activation was 40 seconds in both studies. Note that fully cured resin composites should have the same free total shrinkage, regardless of testing conditions such as curing light, curing time, tip distance, etc, because unlike post-gel shrinkage, total shrinkage is determined by the degree of conversion.

Different values were observed among commercial composites tested in this study. Conventional resin composite, Z100, showed the highest values (3.47\%), followed by Gradia Direct Anterior (3.00\%), Spectra Smart (2.89\%) and Filtek Z350 XT (2.65\%). The lowest values found were for Beautifil II LS (1.18\%), followed by Opus Bulk Fill APS (1.91\%) and Vittra APS (2.14\%). Aura Bulk Fill (2.42\%) presented intermediate values. Therefore, the tested null hypothesis that there would be no difference in volumetric total shrinkage values between conventional, bulk fill and low-shrinkage composites was rejected.

Other studies evaluated total shrinkage of Z350 XT using mercury dilatometer or used an electromagnetic balance for $640 \mathrm{~s} .33,34$ They reported volumetric shrinkage values of $2.0 \%$ and $2.4 \%$, respectively. For Z100, lower total shrinkage values were reported in studies using video-image (2.8\%), mercury dilatometer $(2.7 \%)$, and a drop shape analysis $(2.26 \%)$ when compared to this study $(3.47 \%){ }^{26,35}$ Compared to traditional methods, the optical method thus acquired higher values of total shrinkage because no restrictions were imposed on the samples by the silicone base that allowed free movement of the material. ${ }^{17}$ Many other methods, such as the mercury dilatometer, require silanization and bonding to prevent sample displacement, a factor that hinders free shrinkage and inevitably results in lower shrinkage values.

Current composites have polymeric matrices composed of high molecular weight monomers. Increasing molecular weight of its monomers can help reduce the polymerization shrinkage, such as has been done in some bulk fill resins. ${ }^{36,37}$ Bulk fill materials also use an organic matrix of high translucency and/or have an initiator system designed for better polymerization in depth, allowing the use of restoration increments of 4 to $5 \mathrm{~mm}$ in thickness. ${ }^{38,39}$ With the purpose of reducing the polymerization shrinkage, manufacturers developed composites called low-shrinkage, like Beautifil II LS (Shofu), with shrinkage value of $1.18 \%$ found in this study. Although most of these products are still based on bis-GMA, strategies such as higher filler loadings and changes in the composition of the organic matrix are used by manufacturers. ${ }^{40}$ Beautifil II LS is a low-shrinkage composite based on urethane-diacrylate, Bis-MPEPP, Bis-GMA, TEGDMA and a high filler loading, $83 \mathrm{vol} \%$. According to the manufacturer, it has polymerization shrinkage of 0.85 percent by volume, however the measurement method is not mentioned.

According to the World Dental Federation (FDI) recurrent dental caries, enamel crack formation, marginal discoloration, and adaptation (GAPs) are all considered important clinical issues (evaluated criteria) that may influence the longevity of resin composite restorations. ${ }^{41} \mathrm{All}$ these issues have been associated with polymerization shrinkage stress. Therefore, clinicians should be familiar with polymerization shrinkage and know how to control it when placing restorations.

Considering the use of a DSLR instead of a stereomicroscope, this method was simple to achieve and made it possible to obtain data for the evaluation of total shrinkage. The weakness of total shrinkage is that it has no correlation with shrinkage stresses generated in restored dental structures. ${ }^{42}$ Nevertheless, volumetric total shrinkage contributes to understanding the three-dimensional polymeric network formation during the polymerization process. ${ }^{17}$ Therefore, total shrinkage is a part of the comprehensive approach to study polymerization shrinkage of restorative composite materials, while polymerization shrinkage stress needs to studied using post-gel shrinkage and elastic modulus. The proposed method could measure total shrinkage at different 
times, demonstrating that changes in formulations of bulk fill and low-shrinkage resins differentiate them from conventional composites.

\section{Conclusion}

An optical method using a DSLR camera with a $105 \mathrm{~mm}$ macro lens and ring flash was proposed and found suitable for free total shrinkage evaluation. The results showed lower total shrinkage values for bulk fill and low-shrinkage resin composites.

\section{Acknowledgments}

This study was supported by CAPES and CNPq. The authors thank the University of Tennessee Health Science Center, Memphis, TN, EUA.

\section{References}

1. Bowen RL, Rapson JE, Dickson G. Hardening shrinkage and hygroscopic expansion of composite resins. J Dent Res. 1982 May;61(5):654-8. https://doi.org/10.1177/00220345820610050701

2. Ferracane JL. Hygroscopic and hydrolytic effects in dental polymer networks. Dent Mater. 2006 Mar;22(3):211-22. https://doi.org/10.1016/i.dental.2005.05.005

3. Soares CJ, Faria-e-Silva AL, Rodrigues MP, Vilela AB, Pfeifer CS, Tantbirojn D, et al. Polymerization shrinkage stress of composite resins and resin cements - What do we need to know? Braz Oral Res. 2017 Aug;31(1 suppl 1):e62. https://doi.org/10.1590/1807-3107bor-2017.vol31.0062

4. Mantri SP, Mantri SS. Management of shrinkage stresses in direct restorative light-cured composites: a review. J Esthet Restor Dent. 2013 Oct;25(5):305-13. https://doi.org/10.1111/jerd.12047

5. Jun SK, Kim DA, Goo HJ, Lee HH. Investigation of the correlation between the different mechanical properties of resin composites. Dent Mater J. 2013;32(1):48-57. https://doi.org/10.4012/dmi.2012-178

6. Rosatto CM, Bicalho AA, Veríssimo C, Bragança GF, Rodrigues MP, Tantbirojn D, et al. Mechanical properties, shrinkage stress, cuspal strain and fracture resistance of molars restored with bulk-fill composites and incremental filling technique. J Dent. 2015 Dec;43(12):1519-28. https://doi.org/10.1016/i.jdent.2015.09.007

7. Tantbirojn D, Pfeifer CS, Braga RR, Versluis A. Do low-shrink composites reduce polymerization shrinkage effects? J Dent Res. 2011 May;90(5):596-601. https://doi.org/10.1177/0022034510396217

8. Versluis A, Tantbirojn D. Relationship between shrinkage and stress. In: Daskalaki A, editor. Dental computing and applications: advanced techniques for clinical dentistry. Hershey: IGI Global; 2009. p. 45-64.

9. Pereira RD, Valdívia AD, Bicalho AA, Franco SD, Tantbirojn D, Versluis A, et al. Effect of photoactivation timing on the mechanical properties of resin cements and bond strength of fiberglass post to root dentin. Oper Dent. 2015 Sep-Oct;40(5):E206-21. https://doi.org/10.2341/14-115-L

10. Bicalho AA, Pereira RD, Zanatta RF, Franco SD, Tantbirojn D, Versluis A, et al. Incremental filling technique and composite material_-part I: cuspal deformation, bond strength, and physical properties. Oper Dent. 2014 Mar-Apr;39(2):E71-82. https://doi.org/10.2341/12-441-L

11. Bicalho AA, Valdívia AD, Barreto BC, Tantbirojn D, Versluis A, Soares CJ. Incremental filling technique and composite material—-part II: shrinkage and shrinkage stresses. Oper Dent. 2014 Mar-Apr;39(2):E83-92. https://doi.org/10.2341/12-442-L

12. Soares CJ, Bicalho AA, Verissimo C, Soares P, Tantbirojn D, Versluis A. Delayed photo-activation effects on mechanical properties of dual cured resin cements and finite element analysis of shrinkage stresses in teeth restored with ceramic inlays. Oper Dent. 2016 Sep-Oct;41(5):491-500. https://doi.org/10.2341/15-090-L

13. Bausch JR, Lange K, Davidson CL, Peters A, Gee AJ. Clinical significance of polymerization shrinkage of composite resins. J Prosthet Dent. 1982 Jul;48(1):59-67. https://doi.org/10.1016/0022-3913(82)90048-8

14. Tantbirojn D, Versluis A, Pintado MR, DeLong R, Douglas WH. Tooth deformation patterns in molars after composite restoration. Dent Mater. 2004 Jul;20(6):535-42. https://doi.org/10.1016/i.dental.2003.05.008

15. Ferracane JL, Hilton TJ. Polymerization stress: is it clinically meaningful? Dent Mater. 2016 Jan;32(1):1-10. https://doi.org/10.1016/j.dental.2015.06.020

16. Lovell LG, Berchtold KA, Elliot JE, Lu H, Bowman CN. Understanding the kinetics and network formation of dimethacrylate dental resins. Polym Adv Technol. 2001;12(6):335-45. https://doi.org/10.1002/pat.115

17. Tantbirojn D, Pfeifer CS, Amini AN, Versluis A. Simple optical method for measuring free shrinkage. Dent Mater. 2015 Nov;31(11):1271-8. https://doi.org/10.1016/i.dental.2015.08.150 
18. Rees JS, Jacobsen PH. The polymerization shrinkage of composite resins. Dent Mater. 1989 Jan;5(1):41-4. https://doi.org/10.1016/0109-5641(89)90092-4

19. Ilie N, Hickel R. Investigations on a methacrylate-based flowable composite based on the SDR ${ }^{\mathrm{TM}}$ technology. Dent Mater. 2011 Apr;27(4):348-55. https://doi.org/10.1016/i.dental.2010.11.014

20. Do T, Church B, Veríssimo C, Hackmyer SP, Tantbirojn D, Simon JF, et al. Cuspal flexure, depth-of-cure, and bond integrity of bulk-fill composites. Pediatr Dent. 2014 Nov-Dec;36(7):468-73.

21. Heintze SD, Rousson V. Clinical effectiveness of direct class II restorations - a meta-analysis. J Adhes Dent. 2012 Aug;14(5):407-31. https://doi.org/10.1016/i.dental.2015.01.015

22. Penn RW. A recording dilatometer for measuring polymerization shrinkage. Dent Mater. 1986 Apr;2(2):78-9. https://doi.org/10.1016/S0109-5641(86)80056-2

23. Lai JH, Johnson AE. Measuring polymerization shrinkage of photo-activated restorative materials by a water-filled dilatometer. Dent Mater. 1993 Mar;9(2):139-43. https://doi.org/10.1016/0109-5641(93)90091-4

24. Yamamoto A, Miyazaki M, Rikuta A, Kurokawa H, Takamizawa T. Comparison of two methods for measuring the polymerization characteristics of flowable resin composites. Dent Mater. 2007 Jul;23(7):792-8. https://doi.org/10.1016/i.dental.2006.06.018

25. Gee AF, Feilzer AJ, Davidson CL. True linear polymerization shrinkage of unfilled resins and composites determined with a linometer. Dent Mater. 1993 Jan;9(1):11-4. https://doi.org/10.1016/0109-5641(93)90097-A

26. Sharp LJ, Choi IB, Lee TE, Sy A, Suh BI. Volumetric shrinkage of composites using video-imaging. J Dent. 2003 Feb;31(2):97-103. https://doi.org/10.1016/S0300-5712(03)00005-8

27. Sun J, Lin-Gibson S. X-ray microcomputed tomography for measuring polymerization shrinkage of polymeric dental composites. Dent Mater. 2008 Feb;24(2):228-34. https://doi.org/10.1016/i.dental.2007.05.001

28. Sakaguchi RL, Versluis A, Douglas WH. Analysis of strain gage method for measurement of post-gel shrinkage in resin composites. Dent Mater. 1997 July;13(4);233-9. https://doi.org/10.1016/S0109-5641(97)80034-6

29. Versluis A, Tantbirojn D. Theoretical considerations of contraction stress. Compend Contin Educ Dent. 1999;20 25:S24-32. PMID:11908393

30. Watts DC, Cash AJ. Determination of polymerization shrinkage kinetics in visible-light-cured materials: methods development. Dent Mater. 1991 Oct;7(4):281-7. https://doi.org/10.1016/S0109-5641(05)80030-2

31. Versluis A, Tantbirojn D, Pintado MR, DeLong R, Douglas WH. Residual shrinkage stress distributions in molars after composite restoration. Dent Mater. 2004 Jul;20(6):554-64. https://doi.org/10.1016/j.dental.2003.05.007

32. Tiba A, Charlton DG, Vandewalle KS, Ragain JC Jr. Comparison of two video-imaging instruments for measuring volumetric shrinkage of dental resin composites. J Dent. 2005 Oct;33(9):757-63. https://doi.org/10.1016/i.jdent.2005.02.004

33. Boaro LC, Gonçalves F, Guimarães TC, Ferracane JL, Versluis A, Braga RR. Polymerization stress, shrinkage and elastic modulus of current low-shrinkage restorative composites. Dent Mater. 2010 Dec;26(12):1144-50. https://doi.org/10.1016/j.dental.2010.08.003

34. Naoum SJ, Ellakwa A, Morgan L, White K, Martin FE, Lee IB. Polymerization profile analysis of resin composite dental restorative materials in real time. J Dent. 2012 Jan;40(1):64-70. https://doi.org/10.1016/i.jdent.2011.10.006

35. Tiba A, Charlton DG, Vandewalle KS, Cohen ME. Volumetric polymerization shrinkage of resin composites under simulated intraoral temperature and humidity conditions. Oper Dent. 2005 Nov-Dec;30(6):696-701. https://doi.org/10.2341/04-142

36. Fronza BM, Rueggeberg FA, Braga RR, Mogilevych B, Soares LE, Martin AA, et al. Monomer conversion, microhardness, internal marginal adaptation, and shrinkage stress of bulk-fill resin composites. Dent Mater. 2015 Dec;31(12):1542-51. https://doi.org/10.1016/i.dental.2015.10.001

37. Tauböck TT, Marovic D, Zeljezic D, Steingruber AD, Attin T, Tarle Z. Genotoxic potential of dental bulk-fill resin composites. Dent Mater. 2017 Jul;33(7):788-95. https://doi.org/10.1016/i.dental.2017.04.011

38. Ilie N, Bucuta S, Draenert M. Bulk-fill resin-based composites: an in vitro assessment of their mechanical performance. Oper Dent. 2013 Nov-Dec;38(6):618-25. https://doi.org/10.2341/12-395-L

39. Shortall AC, Palin WM, Burtscher P. Refractive index mismatch and monomer reactivity influence composite curing depth. J Dent Res. 2008 Jan;87(1):84-8. https://doi.org/10.1177/154405910808700115

40. Boaro LC, Gonçalves F, Guimarães TC, Ferracane JL, Pfeifer CS, Braga RR. Sorption, solubility, shrinkage and mechanical properties of "low-shrinkage" commercial resin composites. Dent Mater. 2013 Apr;29(4):398-404. https://doi.org/10.1016/j.dental.2013.01.006

41. Hickel R, Peschke A, Tyas M, Miör I, Bayne S, Peters M, et al. FDI World Dental Federation: clinical criteria for the evaluation of direct and indirect restorations-update and clinical examples. Clin Oral Investig. 2010 Aug;14(4):349-66. https://doi.org/10.1007/s00784-010-0432-8

42. Enochs T, Hill AE, Worley CE, Veríssimo C, Tantbirojn D, Versluis A. Cuspal flexure of composite-restored typodont teeth and correlation with polymerization shrinkage values. Dent Mater. 2018 Jan;34(1):152-60. https://doi.org/10.1016/i.dental.2017.09.019 